\title{
Prognostic significance of circulating tumor cells in non-small cell lung cancer patients undergoing chemotherapy
}

\author{
Bing Tong ${ }^{1, *}$, Yan $X^{1,{ }^{1}}{ }$, Jing Zhao ${ }^{1}$, Minjiang Chen ${ }^{1}$, Jia Xing ${ }^{2}$, Wei Zhong ${ }^{1}$ and \\ Mengzhao Wang ${ }^{1}$ \\ ${ }^{1}$ Department of Respiratory Medicine, Lung Cancer Center, Peking Union Medical College Hospital, Peking Union Medical \\ College, Chinese Academy of Medical Sciences, Beijing, 100730 P.R. China \\ ${ }^{2}$ Cyttel Biosciences Inc., Beijing, 101111 P.R. China \\ *These authors contributed equally to this work \\ Correspondence to: Wei Zhong, email: weizhong3603@sina.com \\ Mengzhao Wang, email: drwang_pumch@sina.com \\ Keywords: circulating tumor cell, non-small cell lung cancer, biomarker, prognosis, chemotherapeutic response \\ Received: June 24, $2017 \quad$ Accepted: August 23, $2017 \quad$ Published: September 23, 2017 \\ Copyright: Tong et al. This is an open-access article distributed under the terms of the Creative Commons Attribution License 3.0 \\ (CC BY 3.0), which permits unrestricted use, distribution, and reproduction in any medium, provided the original author and source \\ are credited.
}

\section{ABSTRACT}

The utility of circulating tumor cells (CTCs) as prognostic biomarkers in nonsmall cell lung cancer (NSCLC) is inconclusive due to the limitations of current CTC detection methods. Using a novel high-efficiency detection method, we determined the ability of CTCs to predict survival and chemotherapeutic responses in NSCLC. In 127 patients with advanced NSCLC, CTCs were counted and analyzed at baseline and during follow-up. Median overall survival (OS) and progression-free survival (PFS) were longer in patients with baseline CTC counts $<8 \mathrm{CTCs} / 3.2 \mathrm{~mL}(20.0 \mathrm{vs}$. 10.4 months $[P=0.009]$ and 7.2 vs. 5.5 months $[P<0.001]$, respectively). Patients with post-treatment increases in the CTC count had poorer OS and PFS than those without increases (12.0 vs. 13.3 months $[P=0.028]$ and 5.2 vs. 6.4 months $[P=$ $0.022]$, respectively). There was no association between the baseline CTC count and chemotherapeutic response $(P=0.734)$. However, the rate of progressive disease in patients with and without post-treatment increases in the CTC count were $15.6 \%$ and $2.4 \%(P=0.042)$, respectively. The baseline CTC count and the change in the CTC count during treatment were both valuable prognostic indicators for NSCLC.

\section{INTRODUCTION}

In recent years, considerable efforts have been made toward the identification of prognostic and predictive biomarkers to guide personalized medicine approaches for patients with advanced non-small cell lung cancer (NSCLC). Circulating tumor cells (CTCs) have been established as a prognostic and predictive biomarker for metastatic breast, colorectal and prostate cancers, with growing evidence suggesting a similar role in lung cancer [1-5]. In a preliminary study [6], we demonstrated the potential of the baseline CTC count as an independent negative prognostic factor for advanced NSCLC. However, there was no statistically significant association between the change in the CTC count and survival outcomes or treatment response. The aim of this study was to further validate the clinical significance of the baseline CTC count and the change in the CTC count during treatment with standard chemotherapy to predict survival outcomes and chemotherapeutic response in patients with advanced NSCLC.

\section{RESULTS}

Patient characteristics

Between September 2012 and September 2015, 127 patients met the inclusion criteria and were included in the primary analysis. Among them, only 73 had their CTCs analyzed before the first, second and third cycle of chemotherapy (Figure 1). Patient characteristics at the point of study entry are summarized in Table 1 . Of the 89 lung adenocarcinoma patients, 72 underwent testing for 
epidermal growth factor receptor (EGFR) mutation and anaplastic lymphoma kinase (ALK) rearrangement. The remaining 17 lung adenocarcinoma patients did not undergo testing because of insufficient tumor tissue. Using the amplification-refractory mutation system, EGFR mutations were detected in 25 patients (L858R point mutations [n $=7]$ and exon 19 deletions $[\mathrm{n}=18]$ ). Using the Ventana immunohistochemistry platform, only 3 patients were identified as having ALK rearrangements. However, all patients who underwent mutational analyses had already undergone standard first-line chemotherapy before the test results were obtained. Eventually, of the 127 patients, 50 were treated with pemetrexed plus cisplatin, 30 with docetaxel plus cisplatin, 29 with gemcitabine plus cisplatin and 18 with paclitaxel plus carboplatin. At the time of the final analysis, 7 patients in the favorable group and 2 patients in the unfavorable group had undergone targeted therapy after the disease had progressed.

\section{CTCs at baseline and during follow-up}

In total, 107 patients were positive for $\geq 2 \mathrm{CTCs} / 3.2$ $\mathrm{mL}$ of blood at baseline: $90, \geq 3 ; 71, \geq 4 ; 56, \geq 5 ; 53, \geq 6 ; 43$, $\geq 7 ; 35, \geq 8$. There was no significant correlation between the favorable or unfavorable baseline CTC count and patient clinicopathological characteristics (Table 2). Among the 73 patients that had their CTCs analyzed before all three cycles of chemotherapy, the median CTC count was 4 (range, 0-80), 6 (range, 0-78) and 2 (range, 0-60) CTCs/3.2 $\mathrm{mL}$ of blood before the first, second and third cycle of chemotherapy, respectively. There was no significant difference between them ( $P=0.469$, Figure 2$)$. After 2 cycles of chemotherapy, 35 patients showed a decrease in the CTC count, 32 patients showed an increase in the CTC count and 6 patients showed no change in the CTC count.

\section{Prognostic significance of CTCs}

At the time of the last follow-up (July 30, 2016), 108 of 127 patients experienced disease progression, and 91 patients died. The median follow-up duration of the 36 surviving patients was 10.3 months (range, 8.7-44.8 mo). Median OS time was significantly longer in the favorable group versus the unfavorable group (20.2 vs. 10.4 mo, respectively; log-rank test, $\mathrm{P}<0.001$; Figure $3 \mathrm{~A}$ ). An unfavorable baseline CTC count and a smoking history were associated with poorer OS, as indicated by step-wise multivariate analysis (Table 3, Supplementary Table 1). The mortality risk was significantly higher for smokers (hazard ratio, 1.680; 95.0\% confidence interval, 1.0492.695; $\mathrm{P}=0.031$ ) and significantly lower for patients with a favorable baseline CTC count (hazard ratio, 0.437; 95.0\% confidence interval, $0.268-0.713 ; \mathrm{P}=0.001)$. There was not a significant association between survival outcomes and other clinical factors, including the Eastern Cooperative Oncology Group (ECOG) performance status (PS), EGFR mutation status, metastasis, age, sex, histology and tumor stage (Supplementary Table 1). Moreover, among the 73 patients that had their CTCs analyzed before all three cycles of chemotherapy, patients with post-treatment increases in the CTC count $(n=32)$ had poorer median OS than those with no changes or post-treatment decreases $(n=41 ; 12.0$ vs. $13.3 \mathrm{mo}, \mathrm{P}=0.028$; Figure $3 \mathrm{~B}$ ).

Furthermore, there was a significant difference in median PFS between the favorable and unfavorable groups (7.2 vs. 5.5 mo; log-rank test, $\mathrm{P}=0.009$; Figure

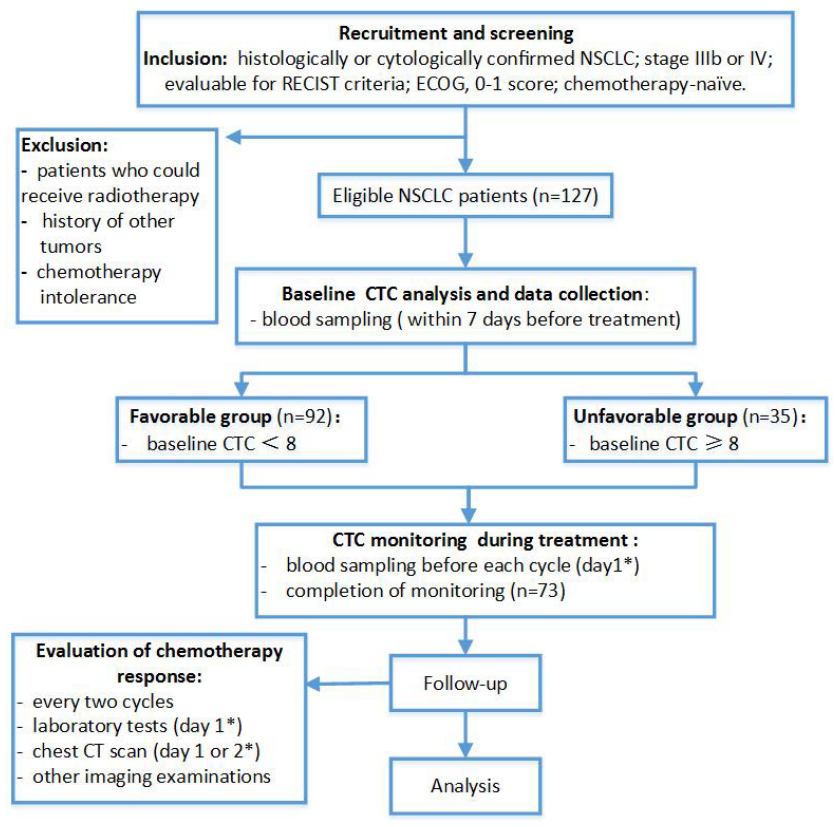

Figure 1: Flow chart of study design. * From the first day of hospitalization. 
Table 1: Patient demographics and clinical characteristics

\begin{tabular}{|c|c|c|}
\hline Characteristics & $\mathrm{n}=\mathbf{1 2 7}$ & $\%$ \\
\hline \multicolumn{3}{|l|}{ Age at baseline, yrs } \\
\hline Median & 59 & \\
\hline Range & $33-78$ & \\
\hline \multicolumn{3}{|l|}{ Gender } \\
\hline Male & 82 & 64.6 \\
\hline Female & 45 & 35.4 \\
\hline Current or former smokers & 80 & 63.0 \\
\hline \multicolumn{3}{|l|}{ ECOG } \\
\hline 0 & 102 & 80.3 \\
\hline 1 & 25 & 19.7 \\
\hline \multicolumn{3}{|l|}{ Histology } \\
\hline $\mathrm{ADC}$ & 90 & 70.9 \\
\hline $\mathrm{SCC}$ & 37 & 29.1 \\
\hline \multicolumn{3}{|l|}{ Tumor stage } \\
\hline Stage IIIb & 21 & 16.5 \\
\hline Stage IV & 106 & 83.5 \\
\hline \multicolumn{3}{|l|}{ EGFR mut } \\
\hline Yes & 25 & 19.7 \\
\hline No & 62 & 48.8 \\
\hline Unknown & 40 & 31.5 \\
\hline \multicolumn{3}{|l|}{ Metastasis location } \\
\hline Bone & 50 & 39.4 \\
\hline Liver & 12 & 9.4 \\
\hline Adrenal gland & 12 & 9.4 \\
\hline Brain & 11 & 8.7 \\
\hline Distant lymphnode* & 13 & 10.2 \\
\hline Others** & 5 & 4.0 \\
\hline
\end{tabular}

ADC, adenocarcinoma; SCC, squamous cell carcinoma.

Distant lymphnode*: Supraclavicular lymph nodes $(\mathrm{n}=8)$, axillary lymph nodes $(\mathrm{n}=3)$ and celiac lymph nodes $(\mathrm{n}=2)$.

Others**: Pericardium $(\mathrm{n}=2)$, kidney $(\mathrm{n}=1)$, meninges $(\mathrm{n}=1)$, and pancreas $(\mathrm{n}=1)$.

3C). In univariate and multivariate analyses, the baseline CTC count was significantly associated with PFS, demonstrating a lower risk of disease progression in the favorable group (hazard ratio, $0.561 ; 95.0 \%$ confidence interval, 0.359-0.875; P = 0.011; Table 3, Supplementary Table 1). In addition, PFS was shorter in patients $(n=32)$ with post-treatment increases in the CTC count than in patients $(n=41)$ without post-treatment increases in the CTC count (5.2 vs. 6.4 mo, $\mathrm{P}=0.022$; Figure 3D).

\section{CTCs and chemotherapeutic responses}

Of the 127 patients enrolled, 125 patients underwent tumor assessments, with 2 patients lost to follow-up after the second cycle of chemotherapy. A partial response (PR) was observed in 28 patients, stable disease (SD) was observed in 83 and progressive disease (PD) was observed in 14. There was no significant difference in the baseline CTC count between the three groups (3.0 vs. 4.0 vs. 5.0; $\mathrm{P}=0.734$; Figure 4; Table 4), and there was no significant 
Table 2: Characteristics of the favorable $(\mathrm{CTC}<8)$ and unfavorable $(\mathrm{CTC} \geq 8)$ groups

\begin{tabular}{|c|c|c|c|c|}
\hline \multirow{2}{*}{ Characteristics } & \multirow{2}{*}{$\begin{array}{c}\text { Total } \\
(\mathrm{n}=127)\end{array}$} & \multicolumn{2}{|c|}{ Baseline CTC count } & \multirow{2}{*}{ P value } \\
\hline & & $<8(\mathrm{n}=92)$ & $\geq 8(n=35)$ & \\
\hline \multicolumn{5}{|c|}{ Smoking history, n (\%) } \\
\hline Yes & $80(63.0)$ & $59(73.8)$ & $21(26.2)$ & \\
\hline No & $47(37.0)$ & $33(70.2)$ & $14(29.8)$ & 0.667 \\
\hline \multicolumn{5}{|l|}{ Histology, n (\%) } \\
\hline $\mathrm{ADC}$ & $89(70.1)$ & $63(70.8)$ & $26(29.2)$ & \\
\hline $\mathrm{SCC}$ & $38(29.9)$ & $29(76.3)$ & $9(23.7)$ & 0.523 \\
\hline \multicolumn{5}{|c|}{ Tumor stage, n (\%) } \\
\hline IIIb & $21(16.5)$ & $17(81.0)$ & $4(19.0)$ & \\
\hline IV & $106(83.5)$ & $75(70.8)$ & $31(29.2)$ & 0.339 \\
\hline \multicolumn{5}{|c|}{ EGFR mutation, $\mathrm{n}(\%)$} \\
\hline Positive & $25(19.7)$ & $20(80.0)$ & $5(20.0)$ & \\
\hline Negative & $62(48.8)$ & $42(67.7)$ & $20(32.3)$ & \\
\hline Unknown & $40(31.5)$ & $30(75.0)$ & $10(25.0)$ & 0.465 \\
\hline \multicolumn{5}{|c|}{ Metastatic site, $\mathrm{n}(\%)$} \\
\hline \multicolumn{5}{|l|}{ Bone } \\
\hline Yes & $50(39.4)$ & $38(76.0)$ & $12(24.0)$ & \\
\hline No & $77(60.6)$ & $54(70.1)$ & $23(29.9)$ & 0.469 \\
\hline \multicolumn{5}{|l|}{ Liver } \\
\hline Yes & $12(9.4)$ & $9(75.0)$ & $3(25.0)$ & \\
\hline No & $115(90.6)$ & $83(72.2)$ & $32(27.8)$ & $1.000 *$ \\
\hline \multicolumn{5}{|l|}{ Adrenal gland } \\
\hline Yes & $12(9.4)$ & $10(83.3)$ & $2(16.7)$ & \\
\hline No & $115(90.6)$ & $82(71.3)$ & $33(28.7)$ & $0.584 *$ \\
\hline \multicolumn{5}{|l|}{ Brain } \\
\hline Yes & $11(8.7)$ & $8(72.7)$ & $3(27.3)$ & \\
\hline No & $116(91.3)$ & $84(72.4)$ & $32(27.6)$ & $1.000 *$ \\
\hline \multicolumn{5}{|c|}{ Distant lymph nodes } \\
\hline Yes & $13(10.2)$ & $10(76.9)$ & $3(23.1)$ & \\
\hline No & $114(89.8)$ & $82(71.9)$ & $32(28.1)$ & $0.957^{*}$ \\
\hline \multicolumn{5}{|c|}{ No. of distant metastases, n (\%) } \\
\hline 0 & $21(16.5)$ & $17(81.0)$ & $4(19.0)$ & \\
\hline 1 & $63(49.6)$ & $43(68.3)$ & $20(31.7)$ & \\
\hline$\geq 2$ & $43(33.9)$ & $32(74.4)$ & $11(25.6)$ & 0.497 \\
\hline
\end{tabular}

*Continuity correction 
$\mathrm{P}=0.469$

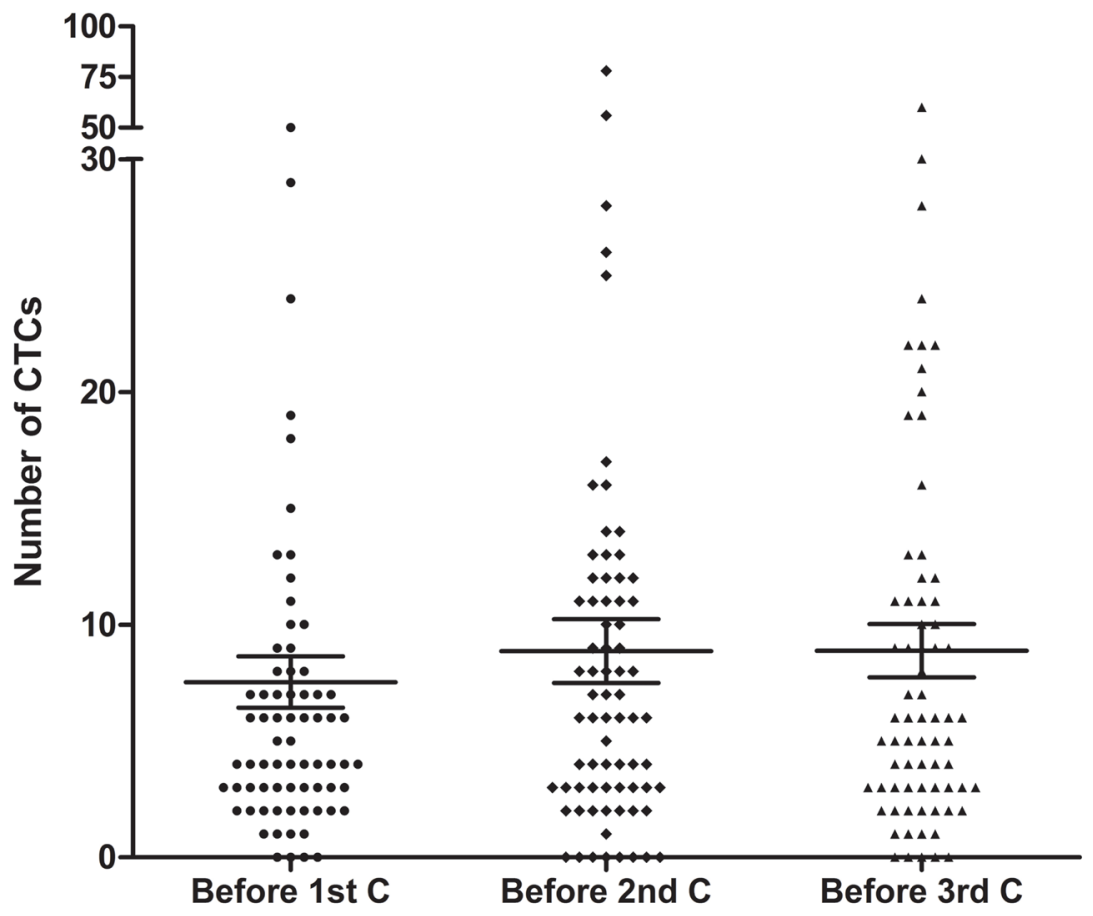

Figure 2: CTC counts before the first, second and third cycle of chemotherapy $(n=73, P=0.469)$.
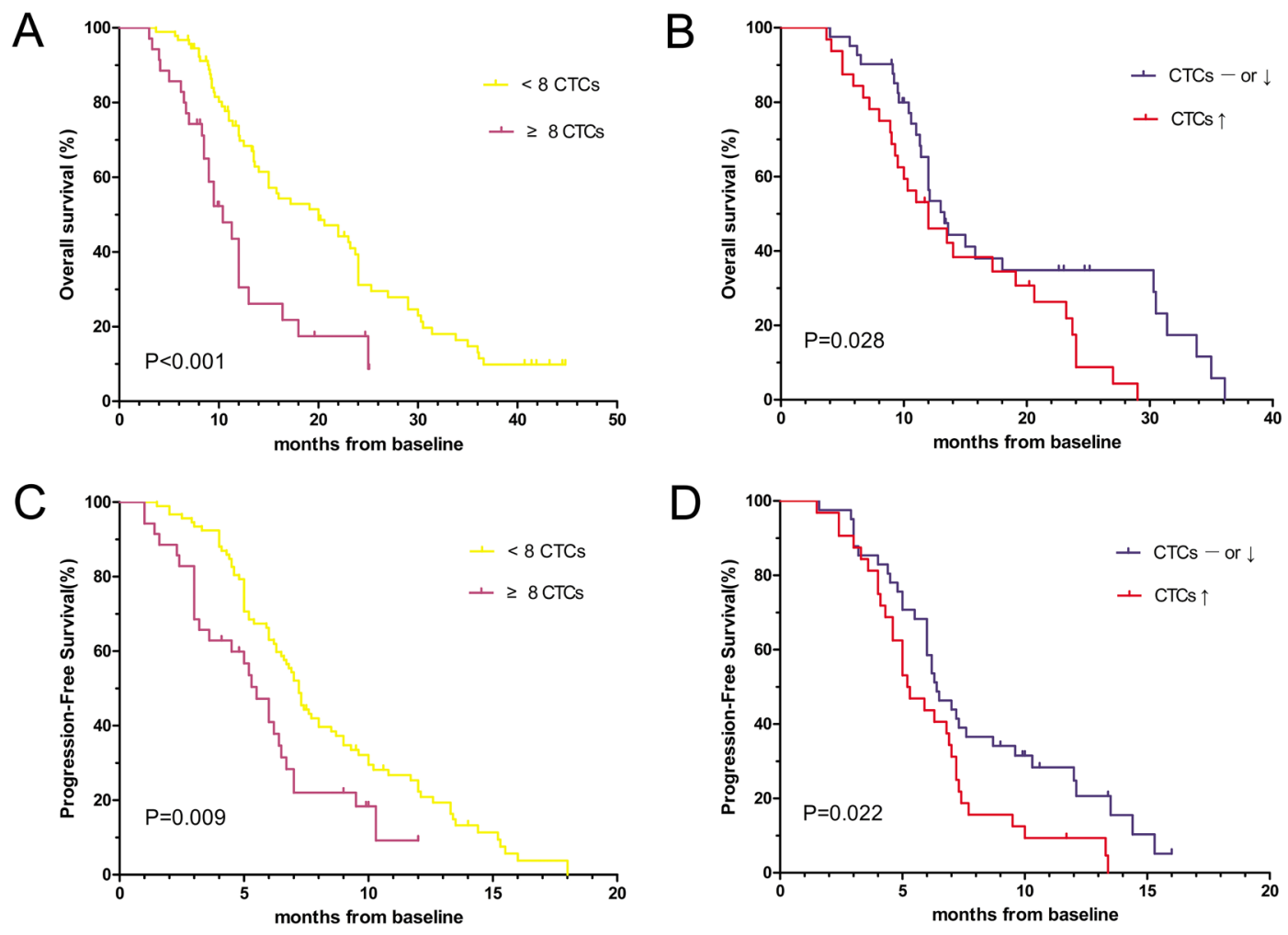

Figure 3: Kaplan-Meier curves of (A) OS according to the baseline CTC count ( $\mathrm{n}=127)$, (B) OS according to the post-treatment CTC count ( $n=73)$, (C) PFS according to the baseline CTC count $(n=127)$ and (D) PFS according to the post-treatment CTC count ( $\mathrm{n}=73)$ in patients with advanced (Stage IIIB or Stage IV) NSCLC. 
Table 3: Univariate and multivariate Cox proportional hazards regression analysis for prediction of PFS and OS

\begin{tabular}{|c|c|c|c|c|}
\hline \multirow{2}{*}{ Variable } & \multicolumn{2}{|l|}{ OS } & \multicolumn{2}{|l|}{ PFS } \\
\hline & HR $(95.0 \%$ CI) & P value & HR $(95.0 \%$ CI $)$ & P value \\
\hline \multicolumn{5}{|c|}{ Univariate Cox proportional hazards regression analysis } \\
\hline Age $:<60$ vs. $\geq 60$ & $0.672(0.443-1.021)$ & 0.063 & $0.906(0.618-1.326)$ & 0.611 \\
\hline Sex: female vs. male & $0.639(0.406-1.007)$ & 0.054 & $0.894(0.598-1.337)$ & 0.586 \\
\hline Smoking history: yes vs. no & $1.836(1.152-2.926)$ & 0.011 & $1.312(0.879-1.960)$ & 0.184 \\
\hline ECOG PS: 0 vs. 1 & $0.828(0.496-1.381)$ & 0.469 & $0.798(0.489-1.304)$ & 0.368 \\
\hline Histology: SCC vs. ADC & $0.713(0.459-1.109)$ & 0.134 & $0.914(0.606-1.377)$ & 0.666 \\
\hline $\begin{array}{l}\text { EGFR mutation: unknown vs. } \\
\text { no vs. yes }\end{array}$ & $1.085(0.832-1.415)$ & 0.546 & $1.281(0.986-1.644)$ & 0.064 \\
\hline Tumor stage: IIIb vs. IV & $0.974(0.550-1.725)$ & 0.927 & $0.798(0.474-1.344)$ & 0.397 \\
\hline Distant metastases: yes vs. no & $1.084(0.611-1.923)$ & 0.783 & $1.348(0.806-2.254)$ & 0.255 \\
\hline Baseline CTCs: $<8$ vs. $\geq 8$ & $0.401(0.246-0.654)$ & $<0.001$ & $0.561(0.359-0.875)$ & 0.011 \\
\hline \multicolumn{5}{|c|}{ Stepwise multivariate Cox proportional hazards regression analysis } \\
\hline Baseline CTCs: $<8$ vs. $\geq 8$ & $0.437(0.268-0.713)$ & 0.001 & $0.561(0.359-0.875)$ & 0.011 \\
\hline Smoking history: yes vs. no & $1.680(1.049-2.695)$ & 0.031 & - & 0.205 \\
\hline
\end{tabular}

difference in the chemotherapeutic response between the favorable and unfavorable groups (Table 4).

Among the 73 patients that had their CTCs analyzed before all three cycles of chemotherapy, 17 exhibited a PR, 50 had SD and 6 had PD. Interestingly, the persistence of a high CTC count was associated with poor response to chemotherapy (Table 4), as PD rates were significantly different between patients with post-treatment increases in the CTC count and patients without post-treatment increases in the CTC count ( $15.6 \%$ vs. $2.4 \%$, respectively, $\mathrm{P}=0.042$ ).

\section{DISCUSSION}

Multiple studies have investigated CTCs and their prognostic role in NSCLC and other cancer types [2, 6-8]. Here, we confirmed that the baseline CTC count and the change in the CTC count during chemotherapy serve as strong independent predictors of OS and PFS in patients with NSCLC.

In this study, CTC detection was performed using the Cyttel method, which combines anti-CD45 immunohistochemistry and fluorescence in situ hybridization. Our detection rate was considerably higher than those obtained using the CellSearch system. The CellSearch system revealed that only $30-50 \%$ of lung cancer patients had $\geq 1 \mathrm{CTC} / 7.5 \mathrm{~mL}$ of blood, and just $20-30 \%$ of patients had $\geq 2$ CTCs/7.5 mL of blood [9-11]. Discrepancies between CTC detection rates might arise as a consequence of using different enrichment strategies.

Epithelial cell adhesion molecule (EpCAM) is expressed at relatively low levels in patients with lung cancer [12]. The widely used CellSearch system and CTC-chip-based platforms detect CTCs via EpCAM and are, thus, inadequate at detecting CTCs in NSCLC. In contrast, the Cyttel method is an immunomagnetic beadbased CTC enrichment system that utilizes a leukocyte depletion mechanism, which allows detection of CTCs via an EpCAM-independent mechanism.

Strong evidence has emerged to support the utility of CTC counts as a prognostic indicator in NSCLC. Consistent with these studies [3, 13-15], our data show that survival rate is significantly poorer in patients with an unfavorable baseline CTC count. Change in the CTC count after chemotherapy was also correlated with survival. Patients with post-treatment increases in the CTC count had poorer clinical outcomes versus those without post-treatment increases. Similar observations have been reported in patients with breast, ovarian and prostate cancers [16-18].

In our study, $8 \mathrm{CTCs} / 3.2 \mathrm{~mL}$ of blood was identified as the most suitable CTC threshold versus 3 or $5 \mathrm{CTCs} / 3.2$ $\mathrm{mL}$ of blood, which was previously reported [1-3]. Notably, the majority of previous studies using lower CTC thresholds were conducted using EpCAM-dependent methods. We postulate that this may have arisen from differences in sensitivity, reproducibility and specificity of different CTC detection techniques. Based on our findings, we recommend a threshold of $8 \mathrm{CTCs} / 3.2 \mathrm{~mL}$ of blood for defining favorable and unfavorable prognostic groups, especially for EpCAM-independent detection methods.

The present study demonstrated that post-treatment increases in the CTC count were significantly correlated with 
Table 4: Association between CTC count and treatment response in the chemotherapy group

\begin{tabular}{|c|c|c|c|}
\hline Parameter & PR & SD & PD \\
\hline \multicolumn{4}{|l|}{ Baseline CTC count } \\
\hline Median & 3 & 4 & 5 \\
\hline$<8(\mathrm{n}=90)$ & $25.6 \%(23)$ & $65.6 \%(59)$ & $8.9 \%(8)$ \\
\hline$\geq 8(\mathrm{n}=35)$ & $14.3 \%(5)$ & $68.6 \%(24)$ & $17.1 \%(6)$ \\
\hline P-value & 0.175 & 0.749 & 0.189 \\
\hline \multicolumn{4}{|c|}{$\begin{array}{l}\text { Change in CTC count after } 2 \\
\text { cycles of chemotherapy }\end{array}$} \\
\hline $\begin{array}{l}\text { Unchanged/decreased } \\
(\mathrm{n}=41)\end{array}$ & $26.8 \%(11)$ & $70.7 \%(29)$ & $2.4 \%(1)$ \\
\hline Increased $(n=32)$ & $18.8 \%(6)$ & $65.6 \%(21)$ & $15.6 \%(5)$ \\
\hline P-value & 0.418 & 0.641 & 0.042 \\
\hline
\end{tabular}

PD, progressive disease; PR, partial response; SD, stable disease.

the rate of PD. Cohen et al. [1] showed that changes in the CTC count were associated with a meaningful sensitivity for predicting PD in colorectal cancer, which is consistent with our findings in NSCLC patients. Of note, we did not detect a relationship between the baseline CTC count and therapeutic response, which is consistent with the findings of our preliminary study [6]. Naito et al. [7] enrolled 51 treatment- naïve small cell lung cancer patients and also did not detect any significant association between therapeutic response and the baseline CTC count when using the CellSearch system. We found that patients with a favorable baseline CTC count tended to have higher PR rates and lower PD rates, however, these findings were not statistically significant. Larger, prospective, multicenter studies are needed to more fully

\section{$P=0.734$}

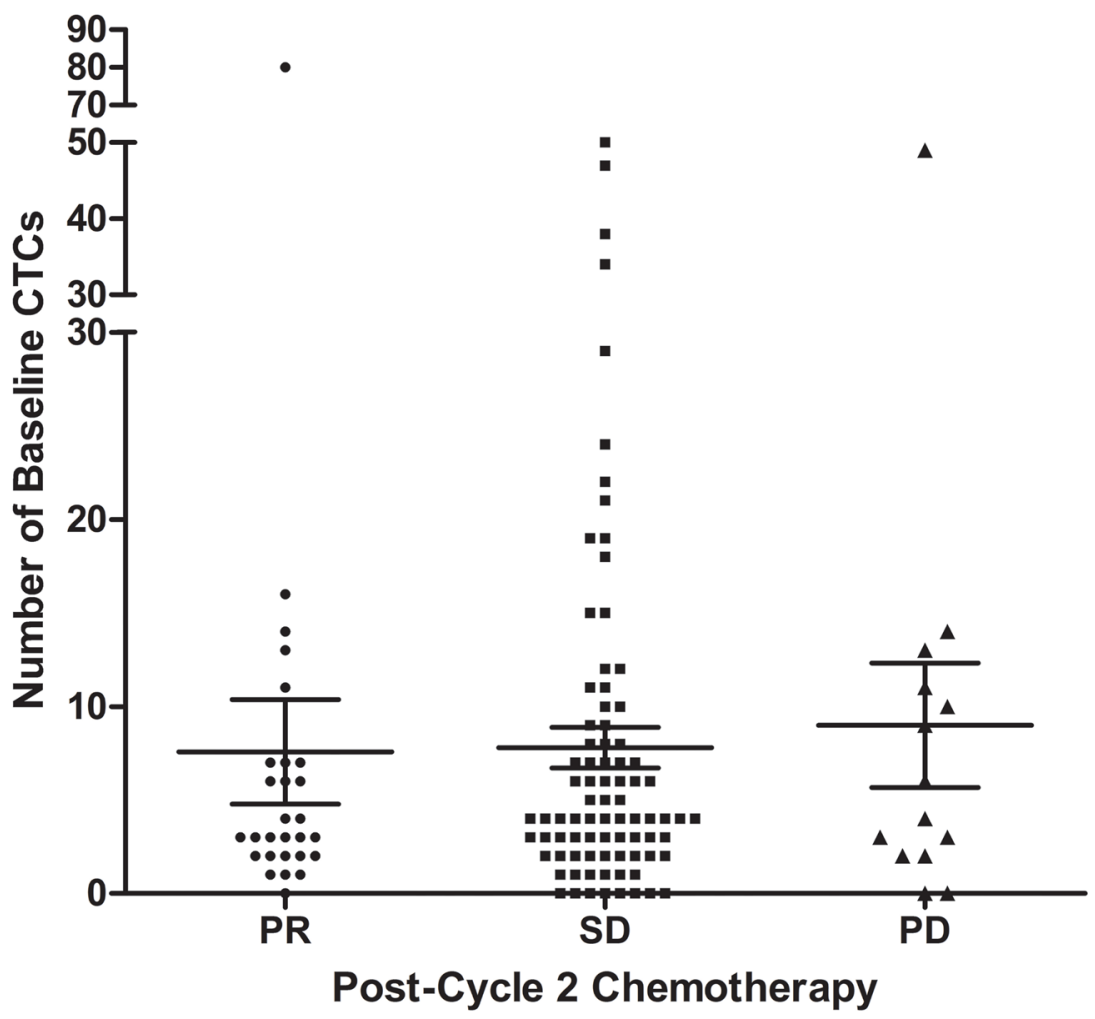

Figure 4: Relationship between the baseline CTC count and chemotherapeutic response $(n=125, P=0.734)$. 
clarify the association between the baseline CTC count and therapeutic response.

Our previous preliminary study found no association between the baseline CTC count and histological type, tumor stage, EGFR mutation status, metastasis site or the number of metastases [6]. In the present study, we also failed to detect any correlation between the CTC count and the above clinical characteristics, which disagrees with a previous report that suggested a higher CTC count was associated with an adenocarcinoma subtype and a greater number of metastatic sites [19]. These contradictory findings are likely due to small sample sizes and the presumption that specific CTC subtypes are important in tumor metastasis.

The main limitations of the present study are the limited proportion of patients who underwent consecutive CTC detection during chemotherapy (73 of 127 patients) and the lack of analysis of patients undergoing targeted therapy as first-line treatment. Moreover, it is difficult to compare our findings with those of other laboratories that used different detection techniques. However, additional data that could address these issues are expected from future, larger-scale, prospective, multicenter studies.

Overall, these findings demonstrate that the baseline CTC count and the change in the CTC count after chemotherapy are of significant utility in monitoring therapeutic response and predicting prognosis in patients with advanced NSCLC.

\section{MATERIALS AND METHODS}

\section{Study design}

This study was approved by the Ethics Committee of the Peking Union Medical College Hospital (Beijing, China). Informed written consent was obtained from each patient before participation in the study. Between September 2012 and September 2015, 127 consecutive treatment-naive patients with histologically proven advanced (Stage IIIb or Stage IV) NSCLC were included. Inclusion and exclusion criteria were applied as described previously [6] (Figure 1). Patients were enrolled at the Peking Union Medical College Hospital (Beijing, China) and later received standard firstline platinum-based chemotherapy. Peripheral blood samples (3.2 mL) were collected for CTC analysis at baseline (within 7 days before starting chemotherapy). Consistent with previous reports, $1 \mathrm{CTC} / 3.2 \mathrm{~mL}$ of blood was classified as CTC-negative, considering the potential for false-positive results, and $\geq 2 \mathrm{CTCs} / 3.2 \mathrm{~mL}$ of blood as CTC-positive [20-22]. Based on our preliminary work, a cut-off threshold of $8 \mathrm{CTCs} / 3.2 \mathrm{~mL}$ of blood was selected for stratifying patients into the favorable ( $<8 \mathrm{CTCs} / 3.2 \mathrm{~mL}$ of blood) and unfavorable ( $\geq 8 \mathrm{CTCs} / 3.2 \mathrm{~mL}$ of blood) prognostic groups [6]. We evaluated the relationships between the baseline CTC count and OS, PFS and treatment responses. Similar analyses were conducted for the CTC count change after 2 cycles of chemotherapy. Chemotherapeutic response was evaluated according to the Response Evaluation Criteria in
Solid Tumors (version 1.1). OS was measured from the date of informed consent to the date of death or last follow-up. PFS was measured from the date of informed consent to the date of disease progression or death.

\section{Analysis of CTCs}

CTCs were identified and counted using the Cyttel method, which combines subtraction enrichment, CD45 immunostaining and fluorescence in situ hybridization (FISH) [21]. The technical details, including the accuracy, linearity, and reproducibility of the method are described in our preliminary study [6]. Briefly, Samples were washed with CS1 buffer (Cyttel Biosciences Co., Ltd., Beijing, China), centrifuged at $650 \mathrm{~g}$ for $5 \mathrm{~min}$ to deplete the serum and processed by lysis of red blood cells with CS2 (Cyttel Biosciences Co., Ltd., Beijing, China). The residual components were re-suspended in CS1 buffer and incubated with immunomagnetic beads conjugated to anti-CD45 monoclonal antibody in order to separate white blood cells. CTCs were detected via CD45 immunostaining and FISH using anti-human CD45 and probes against the centromere of chromosome 8. CD45-negative, centromere of chromosome 8-positive, and 4',6-diamidino-2-phenylindolepositive samples were considered CTC-positive.

\section{Statistical analyses}

The primary analysis of this study was survival and its correlation to favorable and unfavorable baseline CTC counts. From previous studies, we predicted 1-year survival rates of patients with favorable and unfavorable baseline CTC counts to be $60 \%$ and $30 \%$, respectively. Thus, a minimum sample size of 119 patients, including 90 patients with a favorable baseline CTC count and 29 with an unfavorable baseline CTC count, was required to achieve a statistical power of 0.90 , with a two-sided log-rank test at the $5.0 \%$ significance level. In total, 127 eligible patients were enrolled in this study.

Differences amongst groups were analyzed using the Chi-squared test. Clinical factors that were significant predictors of OS and PFS in the univariate analysis were included in the forward stepwise multivariate Cox regression analysis (Wald method). Survival curves were plotted using the Kaplan-Meier method and compared using the log-rank test. All statistical analyses were conducted using Statistical Package for the Social Sciences for Windows (version 17.0) and GraphPad Prism (version 5.0). A P value of $<0.05$ was considered statistically significant.

\section{Abbreviations}

ADC, adenocarcinoma; ALK, anaplastic lymphoma kinase; CD45, leukocyte common antigen; CI, confidence interval; CTC, circulating tumor cell; ECOG, Eastern Cooperative Oncology Group; EGFR, epidermal growth factor receptor; EpCAM, epithelial cell adhesion 
molecule; NSCLC, non-small cell lung cancer; OS, overall survival; PD, progressive disease; PFS, progression-free survival; PR, partial response; PS, performance status; SCC, squamous cell carcinoma; SD, stable disease.

\section{ACKNOWLEDGMENTS}

We thank colleagues at the Lung Cancer Center of Peking Union Medical Hospital for their contribution to sample collection. M. Wang and W. Zhong contributed to the study design and manuscript revisions. B. Tong and Y. $\mathrm{Xu}$ collected samples, performed statistical analyses and wrote the manuscript, and J. Xing was responsible for the CTC detection procedure. All authors read and approved the final manuscript.

\section{CONFLICTS OF INTEREST}

There are no conflicts of interest to disclose.

\section{FUNDING}

There are no funding sources to disclose.

\section{REFERENCES}

1. Cohen SJ, Punt CJ, Iannotti N, Saidman BH, Sabbath KD, Gabrail NY, Picus J, Morse M, Mitchell E, Miller MC, Doyle GV, Tissing H, Terstappen LW, et al. Relationship of circulating tumor cells to tumor response, progressionfree survival, and overall survival in patients with metastatic colorectal cancer. J Clin Oncol. 2008; 26: 3213-3221.

2. Goodman OB Jr, Symanowski JT, Loudyi A, Fink LM, Ward DC, Vogelzang NJ. Circulating tumor cells as a predictive biomarker in patients with hormone-sensitive prostate cancer. Clin Genitourin Cancer. 2011; 9: 31-38.

3. Krebs MG, Sloane R, Priest L, Lancashire L, Hou JM, Greystoke A, Ward TH, Ferraldeschi R, Hughes A, Clack G, Ranson M, Dive C, Blackhall FH. Evaluation and prognostic significance of circulating tumor cells in patients with non-small-cell lung cancer. J Clin Oncol. 2011; 29: 1556-1563.

4. Hou JM, Greystoke A, Lancashire L, Cummings J, Ward T, Board R, Amir E, Hughes S, Krebs M, Hughes A, Ranson M, Lorigan P, Dive C, et al. Evaluation of circulating tumor cells and serological cell death biomarkers in small cell lung cancer patients undergoing chemotherapy. Am J Pathol. 2009; 175: 808-816.

5. Alix-Panabieres C, Pantel K. Challenges in circulating tumour cell research. Nat Rev Cancer. 2014; 14: 623-631.

6. Zhang Z, Xiao Y, Zhao J, Chen M, Xu Y, Zhong W, Xing J, Wang M. Relationship between circulating tumour cell count and prognosis following chemotherapy in patients with advanced non-small-cell lung cancer. Respirology. 2016; 21: 519-525.
7. Naito T, Tanaka F, Ono A, Yoneda K, Takahashi T, Murakami H, Nakamura Y, Tsuya A, Kenmotsu H, Shukuya T, Kaira K, Koh Y, Endo M, et al. Prognostic impact of circulating tumor cells in patients with small cell lung cancer. J Thorac Oncol. 2012; 7: 512-519.

8. Nole F, Munzone E, Zorzino L, Minchella I, Salvatici M, Botteri E, Medici M, Verri E, Adamoli L, Rotmensz N, Goldhirsch A, Sandri MT. Variation of circulating tumor cell levels during treatment of metastatic breast cancer: prognostic and therapeutic implications. Ann Oncol. 2008; 19: 891-897.

9. Tanaka F, Yoneda K, Kondo N, Hashimoto M, Takuwa T, Matsumoto S, Okumura Y, Rahman S, Tsubota N, Tsujimura T, Kuribayashi K, Fukuoka K, Nakano T, et al. Circulating tumor cell as a diagnostic marker in primary lung cancer. Clin Cancer Res. 2009; 15: 6980-6986.

10. Hofman V, Ilie MI, Long E, Selva E, Bonnetaud C, Molina T, Venissac N, Mouroux J, Vielh P, Hofman P. Detection of circulating tumor cells as a prognostic factor in patients undergoing radical surgery for non-small-cell lung carcinoma: comparison of the efficacy of the CellSearch Assay and the isolation by size of epithelial tumor cell method. Int J Cancer. 2011; 129: 1651-1660.

11. Isobe K, Hata Y, Kobayashi K, Hirota N, Sato K, Sano G, Sugino K, Sakamoto S, Takai Y, Shibuya K, Takagi K, Homma S. Clinical significance of circulating tumor cells and free DNA in non-small cell lung cancer. Anticancer Res. 2012; 32: 3339-3344.

12. Allard WJ, Matera J, Miller MC, Repollet M, Connelly MC, Rao C, Tibbe AG, Uhr JW, Terstappen LW. Tumor cells circulate in the peripheral blood of all major carcinomas but not in healthy subjects or patients with nonmalignant diseases. Clin Cancer Res. 2004; 10: 6897-6904.

13. Bayarri-Lara C, Ortega FG, Cueto Ladron de Guevara A, Puche JL, Ruiz Zafra J, de Miguel-Perez D, Ramos AS, Giraldo-Ospina CF, Navajas Gomez JA, DelgadoRodriguez M, Lorente JA, Serrano MJ. Circulating Tumor Cells Identify Early Recurrence in Patients with Non-Small Cell Lung Cancer Undergoing Radical Resection. PLoS One. 2016; 11: e0148659.

14. Dorsey JF, Kao GD, MacArthur KM, Ju M, Steinmetz D, Wileyto EP, Simone CB 2nd, Hahn SM. Tracking viable circulating tumor cells (CTCs) in the peripheral blood of non-small cell lung cancer (NSCLC) patients undergoing definitive radiation therapy: pilot study results. Cancer. 2015; 121: 139-149.

15. Wang J, Wang $\mathrm{K}, \mathrm{Xu}$ J, Huang J, Zhang T. Prognostic significance of circulating tumor cells in non-small-cell lung cancer patients: a meta-analysis. PLoS One. 2013; 8: e78070.

16. Cristofanilli M, Budd GT, Ellis MJ, Stopeck A, Matera J, Miller MC, Reuben JM, Doyle GV, Allard WJ, Terstappen LW, Hayes DF. Circulating tumor cells, disease progression, and survival in metastatic breast cancer. N Engl J Med. 2004; 351: 781-791. 
17. Poveda A, Kaye SB, McCormack R, Wang S, Parekh T, Ricci D, Lebedinsky CA, Tercero JC, Zintl P, Monk BJ. Circulating tumor cells predict progression free survival and overall survival in patients with relapsed/recurrent advanced ovarian cancer. Gynecol Oncol. 2011; 122: 567-572.

18. de Bono JS, Scher HI, Montgomery RB, Parker C, Miller MC, Tissing H, Doyle GV, Terstappen LW, Pienta KJ, Raghavan D. Circulating tumor cells predict survival benefit from treatment in metastatic castration-resistant prostate cancer. Clin Cancer Res. 2008; 14: 6302-6309.

19. Muinelo-Romay L, Vieito M, Abalo A, Nocelo MA, Baron F, Anido U, Brozos E, Vazquez F, Aguin S, Abal M, Lopez RL. Evaluation of Circulating Tumor Cells and Related Events as Prognostic Factors and Surrogate Biomarkers in Advanced NSCLC Patients Receiving First-Line Systemic Treatment. Cancers (Basel). 2014; 6: 153-165.
20. Chen YY, Xu GB. Effect of circulating tumor cells combined with negative enrichment and CD45-FISH identification in diagnosis, therapy monitoring and prognosis of primary lung cancer. Med Oncol. 2014; 31 : 240.

21. Ning N, Zhan T, Zhang $Y$, Chen Q, Feng F, Yang Z, Liu Z, Xu D, Wang F, Guo Y, Xing J, Guan Y, Cui W. Improvement of specific detection of circulating tumor cells using combined CD45 staining and fluorescence in situ hybridization. Clin Chim Acta. 2014 ; 433:69-75.

22. Zhang Y, Wang F, Ning N, Chen Q, Yang Z, Guo Y, Xu D, Zhang D, Zhan T, Cui W. Patterns of circulating tumor cells identified by CEP8, CK and CD45 in pancreatic cancer. Int J Cancer. 2015; 136:1228-33. 